\title{
Metyrapone in Cushing's syndrome: a profile of its use
}

\author{
Zaina T. Al-Salama ${ }^{1}$
}

Accepted: 12 July 2021 / Published online: 6 August 2021

(c) Springer Nature 2021, corrected publication 2021

\begin{abstract}
Metyrapone (Metopirone ${ }^{\circledR}$ ), a pyridine derivative, is a useful treatment option for the management of patients with endogenous Cushing's syndrome, based on evidence from more than six decades of its use in clinical practice, prospective and retrospective studies, as well as case reports. Metyrapone is associated with a rapid onset of action and is effective in reducing cortisol levels and improving clinical and/or biochemical features and cortisol-related comorbidities of Cushing's syndrome. The efficacy of metyrapone was demonstrated in all aetiologies of the condition, when used in a range of clinical settings (including presurgery treatment and when used in combination with other drugs) and in the short and long term. Metyrapone is generally well tolerated when used in the treatment of patients with endogenous Cushing's syndrome, with gastrointestinal adverse events being the most commonly reported.
\end{abstract}

\section{Plain Language Summary}

Endogenous Cushing's syndrome is a rare disease, resulting from cortisol hypersecretion, and is associated with substantial morbidity and mortality. Surgery is the mainstay treatment for the majority of patients with Cushing's syndrome; however, medical therapy is increasingly being used, particularly when surgery is not indicated or is unsuccessful, or while waiting for radiotherapy to be effective. Oral metyrapone (Metopirone ${ }^{\circledR}$ ), a pyridine derivative, is approved for the management of endogenous Cushing's syndrome in the EU. Evidence for the efficacy of metyrapone in the treatment of Cushing's syndrome has been demonstrated in prospective and retrospective studies. Metyrapone has a rapid onset of action $(\approx 2 \mathrm{~h})$, reduces cortisol levels, improves the clinical and/or biochemical features and cortisol-related comorbidities of the disease, and demonstrates sustained efficacy in the long term; the efficacy of metyrapone is evident in a range of clinical settings. Metyrapone is generally well tolerated in patients with endogenous Cushing's syndrome. Given its efficacy and tolerability profile, metyrapone is a useful treatment option for the management of patients with endogenous Cushing's syndrome.

Digital Features for this Adis Drug Q\&A can be found at https:// doi.org/10.6084/m9.figshare.15001206.

\section{What is the rationale for using metyrapone in Cushing's syndrome?}

Metyrapone, a pyridine derivative, was initially used as a test substance for the differential diagnosis of hypothalamus-pituitary-adrenal axis disorders; later, a role of

Supplementary Information The online version contains supplementary material available at https://doi.org/10.1007/s40267021-00853-y.

Zaina T. Al-Salama

dtp@adis.com

1 Springer Nature, Mairangi Bay, Private Bag 65901, Auckland 0754, New Zealand metyrapone for the treatment of hypercortisolism was established [1]. Endogenous Cushing's syndrome is a rare disease associated with substantial morbidity and mortality [2], resulting from cortisol hypersecretion. Cushing's syndrome can be broadly grouped into adrenocorticotropic hormone (ACTH)-dependent $[\approx 80 \%$; including ACTH-secreting pituitary adenoma (Cushing's disease; 60-70\%) and ectopic ACTH-syndrome (EAS; 5-10\%)] and ACTH-independent $(\approx 20 \%$; including cortisol-secreting adrenal adenoma, adrenocortical cancer, ACTH-independent macronodular adrenal hyperplasia and primary pigmented nodular adrenal disease) forms of the disease [1,3].

Treatment of Cushing's syndrome aims to eliminate the primary cause of hypercortisolism and achieve remission, in order to eliminate the associated signs and symptoms and improve the patient's quality of life [4]. Effective treatment of Cushing's syndrome includes normalisation of cortisol 


\section{Adis evaluation of metyrapone (Metopirone ${ }^{\circ}$ ) in}

the management of Cushing's syndrome

Indicated in the EU for the management of patients with endogenous Cushing's syndrome and as a diagnostic test of adrenocorticotropic hormone (ACTH) insufficiency and in the differential diagnosis of ACTH-dependent Cushing's syndrome

Associated with a rapid onset of action $(\approx 2 \mathrm{~h})$, a reduction in cortisol levels and improvements of clinical and/ or biochemical features of Cushing's syndrome

Efficacy maintained in the long term

Generally well tolerated, with most adverse events being gastrointestinal

levels, as well as improvement or normalisation of comorbidities associated with hypercortisolism (e.g. hypertension) by directly treating the cause of Cushing's syndrome and through relevant adjunctive treatments (e.g. antihypertensive therapy) [4]. Although surgery is the mainstay treatment for the majority of patients with Cushing's syndrome, medical therapy (including steroidogenesis inhibitors) is increasingly being used, particularly when surgery is not indicated or is unsuccessful, or while waiting for radiotherapy to be effective $[4,5]$.

Metyrapone (Metopirone ${ }^{\circledR}$ ) is approved in the EU for the management of patients with endogenous Cushing's syndrome. Table 1 provides a summary of the prescribing information for oral metyrapone as approved in the EU [6]. Consult local prescribing information for further details. Discussion of the use of metyrapone in the other approved indications [as a diagnostic test for ACTH insufficiency and in the differential diagnosis of ACTH-dependent Cushing's syndrome in the EU [6], or as a diagnostic drug for testing hypothalamic-pituitary ACTH function in the US [7]] is beyond the scope of this review.

\section{How does metyrapone work in Cushing's syndrome?}

Metyrapone exerts its pharmacological effect in Cushing's syndrome by reducing cortisol production in the adrenals by potently inhibiting the 11-beta-hydroxylase enzyme (CYP11B1), which is responsible for the final step in cortisol synthesis (Fig. 1) [1, 43, 44]; the resultant reduction in serum cortisol levels is associated with a consequent increase in the concentrations of ACTH and 11-deoxycortisol. The compensatory increase in ACTH levels may drive further steroidogenesis and overcome the blockade exerted by metyrapone (i.e. cortisol escape) [44].

Metyrapone and its active metabolite, metyrapol, dosedependently inhibit the two highly homologous isoforms of 11-hydroxylase, 11 $\beta$-hydroxylase (CYP11B1) and 18-hydroxylase (CYP11B2), and consequently inhibit cortisol and aldosterone production $[1,44]$. In HAC15 cell lines, the half maximal inhibitory concentrations of metyrapone

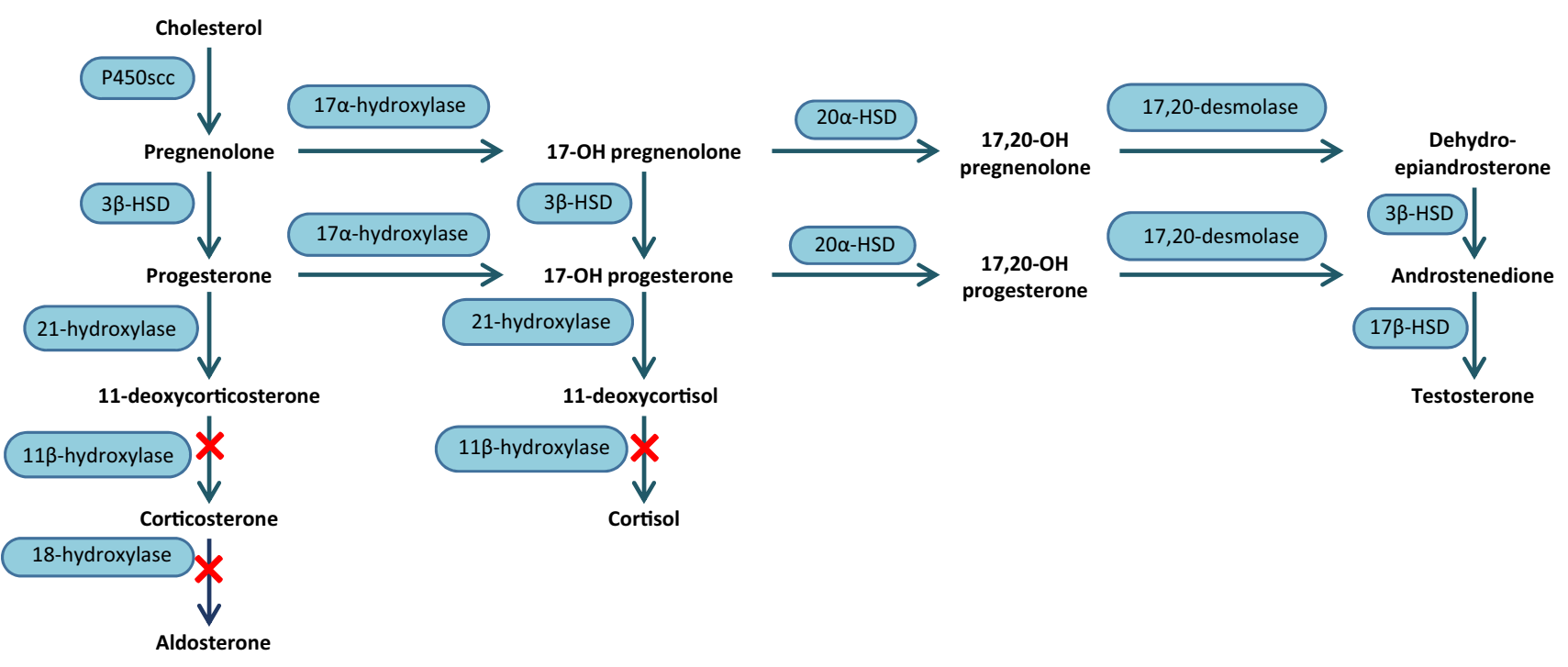

Fig. 1 Metyrapone inhibition of adrenal steroid biosynthesis [1, 44, 54]. Figure adapted from the EMA Public Assessment Report: Ketoconazole HRA [54]. A red cross indicates metyrapone inhibition of the enzymatic step. HSD hydroxysteroid dehydrogenase, P450scc cholesterol side chain cleavage enzyme 
Table 1 Summary of the prescribing information of metyrapone (Metopirone ${ }^{\circledR}$ ) in endogenous Cushing's syndrome in the EU [6]

How is metyrapone available and packaged?

Soft capsules each containing $250 \mathrm{mg}$ of metyrapone, packaged in a high-density polyethylene bottle of 50 capsules with a tamper evident screw cap

What are the dosage recommendations for metyrapone?

Initial dose

$750 \mathrm{mg} /$ day ( 3 capsules), but may vary (250-1000 mg/day) [1-4 capsules] depending on the cause of Cushing's syndrome and severity of hypercortisolism (lower doses in patients with mild disease, adrenal adenoma or hyperplasia or up to $1500 \mathrm{mg} / \mathrm{day}$ [6 capsules] for patients with severe hypercortisolism)

May be initiated at a dose of $750 \mathrm{mg} /$ day [3 capsules]

Maintenance dosage $\quad 500-6000 \mathrm{mg} /$ day [2-24 capsules] in three or four divided doses

Dosage adjustment Individualise dosage adjustment depending on tolerability and to meet patient requirements

Adjust daily dose after a few days of initiating treatment; aim to lower the mean plasma/serum cortisol levels ${ }^{\mathrm{a}}$ and/or the $24 \mathrm{~h}$ urinary free cortisol levels to a normal target value or until the maximum tolerated dose is reached

Monitor plasma/serum cortisol levels and/or 24-h free urinary cortisol levels once weekly to allow for further dose adjustments (dose-adjustment period 1-4 weeks)

Monitor less frequently (every 1-2 months) when cortisol levels are close to optimal levels

Method of administration With milk or after a meal (to minimise nausea and vomiting)

What are the contraindications to the use of metyrapone?

Manifest primary adrenocortical insufficiency

Hypersensitivity to metyrapone or any of the excipients

How should metyrapone be used in special populations?

Paediatric patients No specific dosage adjustment required (limited data; 21 case reports [8-23], including 1 case of rectal administration [21]); adjust based on cortisol levels and tolerability

Elderly patients ( $\geq 65$ years) No specific dosage adjustment required (limited data) [11 case reports [16, 24-26]]

What other special warnings and precautions pertain to the use of metyrapone?

Excipients $^{\mathrm{b}} \quad$ Delayed allergic reactions may occur

Assay methods Measure plasma/serum and urine cortisol levels using a reliable assay without cross-reactivity with steroids precursors (e.g. a specific immuno-assay or a liquid chromatography-mass spectrometry method) to allow accurate dose adjustment

Supervision

Monitor and instruct patients on the signs and symptoms of hypocortisolism; manage hypocortisolism with temporary exogenous steroid replacement therapy and/or dose modification (reduction or interruption), as necessary

Patients with severe hypercor- Consider appropriate prophylactic treatment for opportunistic infections (e.g. Pneumocystis jirovecii pneumonia) during treatment tisolism

Hypertension Long-term treatment can cause hypertension (because of excessive secretion of desoxycorticosterone)

Breastfeeding Discontinue during treatment as risk to newborns/infants cannot be excluded (insufficient information) [one case report [27]]

Can metyrapone be used in pregnant women?

Use in pregnant women and in women of childbearing potential not using contraception is not recommended unless clearly necessary; monitor blood pressure in pregnant women receiving metyrapone and manage hypertension as needed

Limited data in pregnant women (20 pregnancies in 17 women $[6,13,28-41])$

What clinically relevant drug interactions may potentially occur with metyrapone?

Paracetamol Concomitant use with metyrapone may potentiate paracetamol toxicity [42]

What are the signs, symptoms and laboratory findings indicative of metyrapone overdose, and how can it be treated?

Signs and symptoms

Non-specific symptoms: nausea, vomiting, abdominal pain, diarrhoea, weakness, anorexia, fatigue, hypotension

Laboratory findings

Hyponatraemia, hypochloraemia, hyperkalaemia and low morning serum cortisol; signs and symptoms of acute poisoning may be aggravated or modified in patients receiving insulin or oral anti-diabetic treatment

Treatment

Requires urgent medical attention (no specific antidote); consider activated charcoal (within $1 \mathrm{~h}$ of overdose)

Administer a large dose of hydrocortisone at once, together with intravenous saline and glucose, and repeat as necessary; monitor blood pressure and fluid electrolyte balance for a few days

${ }^{a}$ Calculated from the average of 5-6 plasma/serum samples obtained throughout a day or from cortisol levels obtained just before the morning dose

${ }^{\mathrm{b}}$ Sodium ethyl parahydroxybenzoate and sodium propyl parahydroxybenzoate

were $0.0678 \mu \mathrm{M}$ and $0.0739 \mu \mathrm{M}$ under basal conditions and ACTH stimulation, respectively [45].

Metyrapone has also demonstrated extra-adrenal effects by influencing peripheral glucocorticoid metabolism [46], that contribute to the reduction of plasma cortisol levels [47,
48]. Following oral administration of metyrapone $(40 \mathrm{mg} / \mathrm{kg})$ in healthy volunteers, the levels of cortisol begin to decrease within 15-30 min, with maximal reduction in cortisol levels obtained in $\approx 2 \mathrm{~h}$ and maintained for $\approx 7 \mathrm{~h}$ post-dose [49]; 
this duration of effect allows for more flexibility in adjusting the frequency of dosing (i.e. three or four times daily).

Following oral administration, metyrapone is rapidly absorbed and eliminated from the plasma [6]; the peak plasma concentration is reached $1 \mathrm{~h}$ after administration [50] and the elimination half-life of metyrapone is $\approx 2 \mathrm{~h}$ [6]. Metyrapol, the main active metabolite of metyrapone, takes twice as long as metyrapone to be eliminated from plasma. Following an initial dose of metyrapone ( $4.5 \mathrm{~g})$, $5.3 \%$ and $38.5 \%$ of the total dose was excreted in the urine as metyrapone and metyrapol [6].

\section{How should metyrapone be used in Cushing's syndrome?}

The two ways to use steroidogenesis inhibitors, including metyrapone, are in a dose titration or a block-and-replace regimen [44]. In a dose titration, the initial dose is up-titrated in accordance with the biochemical response, whereas in a block-and-replace regimen, a high dose is usually initiated and quickly up-titrated to the maximum tolerated dose with the addition of concomitant glucocorticoid replacement therapy. The aim of a block-and-replace regimen is to completely suppress cortisol production and replace glucocorticoids to avoid hypoadrenalism. The choice between the two treatment regimens is largely driven by the clinician's experience and preference, although there are cases where a block-and-replace is the preferred option (e.g. evidence of cyclical disease, very severe hypercortisolaemia). Albeit the safety of a block-and-replace regimen, care is needed to ensure that incompletely treated and persistent hypercortisolaemia is not made worse by the unnecessary addition of exogenous glucocorticoids [44].

Metyrapone capsules are indicated in the EU for the management of patients with endogenous Cushing's syndrome (Table 1) [6]. Metyrapone may be initiated at a dose of $750 \mathrm{mg}$ /day (3 capsules), although the initial metyrapone daily dose may vary depending on the severity of hypercortisolism and the cause of Cushing's syndrome (Table 1). A lower initial dose of metyrapone may be used in patients with mild Cushing's syndrome, adrenal adenoma or hyperplasia, whereas a higher initial dose (up to $1500 \mathrm{mg} /$ day; 6 capsules) may be used for patients with severe disease [6]. The daily dose of metyrapone should be adjusted after a few days, with weekly monitoring to be performed to allow for further dose adjustments as necessary; less frequent monitoring is required once cortisol levels are close to optimal levels (Table 1). Alternatively, a block-and-replace regimen may be used as appropriate (e.g. in case of rapid doseescalation or for patients with cyclic Cushing's syndrome), where physiological corticosteroid replacement therapy is added to complete cortisol blockade by metyrapone; physiological corticosteroid replacement therapy should be initiated once serum or urine cortisol is in the normal range and the metyrapone doses are increased to achieve complete suppression of cortisol secretion [6].

Treatment with metyrapone may lead to a rapid decrease in circulating levels of cortisol (and potentially to hypocortisolism/hypoadrenalism); therefore, monitoring of clinical and biochemical responses under the supervision of a specialist is recommended (Table 1) [6]. Given that the interaction potential of metyrapone is partly unknown, caution is recommended when initiating or discontinuing treatment with other medicinal products; suitable action should be taken if changes are seen in the effect and/or safety of metyrapone or the co-administered drug [6].

Given that the data for the use of metyrapone in pregnant women are limited, the use of metyrapone in pregnancy is not recommended unless clearly necessary; the efficacy of metyrapone in controlling hypercortisolism in pregnant women has been demonstrated in a limited number of case reports (Table 1).

Currently available immunoassay methods for serum cortisol are susceptible to interference in metyrapone-treated patients because of increased steroid precursors [51-53]; dose adjustments of metyrapone should be based on cortisol measurements using a reliable assay without the potential for cross-reactivity (Table 1).

\section{What is the evidence for using metyrapone to treat patients with Cushing's syndrome?}

Evidence for the efficacy (range, 50-70\% across key studies) of metyrapone in the treatment of Cushing's syndrome is demonstrated in prospective (Table 2) and retrospective (Table 3) studies, as well as case series and individual case reports. Based on the available data, treatment with metyrapone was associated with a rapid onset of action and was effective in reducing cortisol levels and improving clinical and/or biochemical features and cortisol-related comorbidities of the disease (Tables 2 and 3). Metyrapone has been widely used in the management of Cushing's syndrome for more than six decades [44], with cumulative literature data (including case series and case reports) demonstrating that metyrapone has been used in $\approx 700$ patients with Cushing's syndrome of all aetiologies; the majority $(56 \%)$ of published cases were those of Cushing's disease [26\% of published cases were EAS and $16 \%$ of cases were adrenal adenoma tumours (benign and malignant) and hyperplasia] [55]. Metyrapone was also used in a range of clinical settings, including as a primary treatment if surgery is not feasible or after surgical failure, or as a presurgery treatment; metyrapone was used as monotherapy or in combination 
with other agents (e.g. ketoconazole, mitotane) [Tables 2 and 3].

Metyrapone has a rapid onset of action and is an effective long-term medical treatment to control serum cortisol levels in patients with endogenous Cushing's syndrome. Some key evidence is available from a recent prospective, observational longitudinal study of patients with Cushing's syndrome $(n=31)$ treated with metyrapone for $\geq 1$ month as primary treatment $(n=16)$ or after surgical failure $(n=15)$ [5]. The median treatment duration was 9 months and the median metyrapone dose at the last visit was $1000 \mathrm{mg}$ (4 capsules); 25, 18, 13 and 6 patients, respectively, completed 3, 6, 12 and 24 months of metyrapone treatment [5]. Metyrapone had a rapid onset of action and sustained efficacy, achieving urinary free cortisol (UFC) normalisation (primary endpoint) in the majority of treated patients (Table 2) [5]. After the first month of metyrapone treatment, the median reduction in mean UFC (mUFC) levels from baseline was $-67 \%$; after 3 months of treatment, there was a median reduction from baseline of $70 \%$ (Table 2) [5]. Notably, amongst patients with severe hypercortisolism at baseline $(n=10)$, the median reduction in mUFC levels after the first month of treatment was $-86 \%$ [5]. Normalisation of mUFC was achieved in the first month of treatment amongst patients with mild, moderate and severe hypercortisolism, whereas control of cortisol secretion was achieved within 3-6 months of treatment amongst patients with very severe hypercortisolism [5]. At the time of the last visit, the majority of patients had normalised mUFC (irrespective of hypercortisolism severity at baseline) [Table 2] [5].

Mean late-night salivary cortisol (mLNSC) levels were reduced from baseline (all patients presented with elevated levels at baseline), but remained above the upper limit of normal (ULN) at each scheduled visit [5]. The median reduction in mLNSC levels from baseline was $57 \%$ at 1 month and 63\% after 3 months of treatment; in the subset of patients with severe hypercortisolism at baseline, the median reduction in mLNSC levels was $80 \%$ after 1 month of treatment. Over time, the proportion of patients at each scheduled visit achieving mLNSC normalisation increased steadily reaching $37 \%$ at the last scheduled visit (Table 2), with complete recovery of cortisol rhythm at the last available visit obtained in patients with normal mUFC or mild hypercortisolism at baseline. A longer treatment period (3-6 months) was needed to reduce mLNSC levels amongst patients who had severe or very severe hypercortisolism at baseline [5].

When considering different types of Cushing's syndrome, baseline characteristics of patients with EAS were less favourable (e.g. older age, higher baseline levels of mUFC) compared with Cushing's disease and bilateral adrenal Cushing's syndrome patients; however, metyrapone doses and cortisol levels were generally similar across the different subtypes of Cushing's syndrome at the time of the last visit [5]. Escape from metyrapone treatment, associated with worsening of cortisol-related signs and symptoms, occurred in three patients (who had normalised mUFC levels) after 9 months of metyrapone treatment [5]. There was a significant ( $p<0.001$ vs. baseline) weight reduction in patients who had mUFC $<$ ULN at the last visit, and after $\geq 3$ and 6 months of metyrapone treatment. Some patients with baseline cortisol-related comorbidities required medication adjustments (Table 2).

The rapid onset of action and efficacy of metyrapone in patients with endogenous Cushing's syndrome were also confirmed in results of the 12-week interim analysis of PROMPT, the first prospective study to document the efficacy of metyrapone using modern assay techniques [56]. The PROMPT study was an open-label, single-arm, international phase III/IV study that investigated the efficacy of metyrapone in adults who were newly diagnosed with endogenous Cushing's syndrome (any aetiology, except advanced adrenal carcinoma) or with recurrent or persistent Cushing's disease (after transsphenoidal surgery) [56]. Eligible patients had to have three UFC values (measured over $24 \mathrm{~h}$ ) each $\geq 50 \%$ above the ULN ( $165 \mathrm{nmol} / 24 \mathrm{~h})$. The starting dose of metyrapone was based on the severity of hypercortisolism at baseline ( $\leq 5$ or $>5 \times \mathrm{ULN}$ ), and was administered in 3-4 divided doses and individually titrated based on cortisol levels in urine and serum over 12 weeks to achieve normal urine and/or serum cortisol levels (period 1: dose-titration period). After 12 weeks, patients who had a mean value of three UFCs (mUFC) less than twice the ULN could continue to receive metyrapone for another 24 weeks (period 2: optional extension period) [56].

After 12 weeks of treatment with metyrapone, the majority of patients were responders (Table 2). The primary endpoint of mUFC normalisation (i.e. mUFC $\leq$ ULN) was achieved by $47 \%$ of patients; an additional $33 \%$ of patients had $\geq 50 \%$ decrease in mUFC from baseline after 12 weeks of treatment with metyrapone, without achieving normalisation (i.e. partial responders) [56]. Normalisation of LNSC was observed in $22 \%$ of treated patients. The decrease in median mUFC and LNSC from baseline was rapid, starting at week 1 and continuing to decrease until week 12 (Table 2); the median time to eucortisolaemia was 34 days [56]. Of note, $86 \%$ had mUFC $\leq 2 \times$ ULN at week 12 and were eligible to enter the extension period of 6 months [57].

In terms of secondary endpoints, metyrapone normalised or improved physical signs and symptoms in the majority of patients (66\%), was associated with a median decrease of -4 and $-5 \mathrm{mmHg}$ in systolic and diastolic blood pressure and a 10 points improvement in Cushing's quality of life (QoL), at week 12. Moreover, metyrapone was generally associated with relative improvements from baseline in 
Table 2 Summary of key $(n>6)$ prospective studies demonstrating the efficacy of metyrapone in the treatment of Cushing's syndrome

Study details

Key efficacy results

\begin{tabular}{lll}
\hline No. of pts $\quad$ Tx & $\begin{array}{l}\text { Median MET dosage } \\
\text { (no. of MET capsules) }\end{array}$
\end{tabular}

\begin{tabular}{cl}
\hline Nieman et al. (2020) & [PROMPT; 12-wk interim analysis] [56] \\
\hline 50 (49 analysed; 44 & MET for endogenous $1500 \mathrm{mg} / \mathrm{day}$ (6) \\
with CD, 4 with & CS or any aetiology \\
EAS, 1 with CS of & (except advanced \\
adrenal cause) & adrenal carcinoma) \\
& $\begin{array}{l}\text { or for recurrent/ } \\
\text { persistent CD after } \\
\text { TSS }\end{array}$
\end{tabular}

Nieman et al. (2020) [PROMPT; 36-wk extension] [58]

41 (35 pts completed MET Not reported the extension) Majority (80\%) of pts were responders having either mUFC
normalisation a in $23 / 49$ pts $(47 \%)$ or $\geq 50 \%$ of mUFC from BL
(without normalisation) in $16 / 49$ pts (33\%) at wk 12
Median mUFC and LNSC levels $\downarrow$ rapidly (wk 1 ) by a median of $49 \%$
and 36\% and were sustained reaching a $\downarrow$ of $73.5 \%$ and 55\% (wk 12)
LNSC levels normalised in $22 \%$ of pts at wk 12
Improved clinical signs of hypercortisolism, associated comorbidities
and Cushing's QoL at wk 12

mUFC normalisation maintained: mUFC levels normalised in $49 \%$ of pts and $\geq 50 \% \downarrow$ of mUFC from BL without normalisation in a further $23 \%$ of pts

Median mUFC levels $\downarrow$ was maintained (70\%) and LNSC levels $\downarrow$ was further improved, reaching $72 \%$ at week 36

LNSC normalisation in $27 \%$ of pts

Clinical (physical symptoms, cardiovascular and metabolic parameters) and Cushing's QoL improvements sustained over time

Ceccato et al (2018) [5]

31 (20 with CD, $6 \quad$ MET as primary tx or $1000 \mathrm{mg} /$ day (4) with EAS and 5

with adrenal CS)

mUFC and mLNSC levels $\downarrow$ by a median of $67 \%$ and $57 \%$ from BL after 1 mo. and by $70 \%$ and $63 \%$ from BL after 3 mo.

mUFC levels normalisation in $68 \%$ of all pts at 3 mo.; mUFC levels $\downarrow$ after 1 and 3 mo., with $\downarrow$ levels sustained up to 12 and 24 mo.

mUFC levels normalised in $71 \%$ of all pts (independent of hypercortisolism severity at BL) at the last visit, and in $62 \%$ of a subset of pts with $\mathrm{mUFC}>\mathrm{ULN}$ at BL

mLNSC levels normalised in $37 \%$ of pts (last visit); normalisation of both mUFC and mLNSC (combined) achieved in $\approx 50 \%$ of pts after $12-24 \mathrm{mo}$.

MET was effective as primary medical therapy (i.e. before surgery): median reduction of mUFC and mLNSC levels at 3 mo. was $80 \%$ and $75 \%$ (both $p<0.01$ ) from $\mathrm{BL}$

In CD pts, MET achieved normalisation of mUFC after surgical failure in $12 / 14$ pts $(86 \%)$ and before surgery in $1 / 6$ pts $(17 \% ; p=0.007)$

In pts with hypertension before enrolment $(n=24), 42 \%$ achieved BP normalisation, $21 \%$ required uptitration of antihypertensive tx and $17 \%$ stopped their antihypertensive tx

$\downarrow$ the dose or number of antidiabetic drugs in $64 \%$ of pts with impaired fasting glucose or diabetes before enrolment $(n=11)$

Puglisi et al. (2018) [68]

7 with ACTHindependent CS due to adrenal adenoma (4 with mild to moderate hypercortisolism and 3 with severe hypercortisolism)
MET for $3 \mathrm{mo}$. before $750 \mathrm{mg} /$ day (3) to adrenalectomy

UFC levels normalised in all pts at days 65 and 82 ; median $\%$ change compared with BL of $-90 \%$ and $-89 \%$ ( $p<0.02$ for both)

At end of tx, $\downarrow$ levels of morning serum cortisol (median $\%$ change from $\mathrm{BL}-35 \% ; p<0.05)$ and of salivary cortisol at 08:00 $\mathrm{h}(-63 \%$; $p=0.06), 16: 00 \mathrm{~h}(-67 \% ; p<0.04)$ and $23: 00 \mathrm{~h}(-80 \% ; p<0.02)$

Clinical improvements at day 82 (from BL) in health-related QoL score, systolic and diastolic BP (all $p<0.05)$ 
Table 2 (continued)

\begin{tabular}{|c|c|c|c|}
\hline \multicolumn{3}{|l|}{ Study details } & \multirow[t]{2}{*}{ Key efficacy results } \\
\hline No. of pts & $\mathrm{Tx}$ & $\begin{array}{l}\text { Median MET dosage } \\
\text { (no. of MET capsules) }\end{array}$ & \\
\hline \multicolumn{4}{|c|}{ Kamenický et al. (2011) [30] } \\
\hline \multirow{3}{*}{$\begin{array}{l}11 \text { with severe } \\
\text { hypercortisolism } \\
\text { (ACTH-dependent } \\
\text { CS) }\end{array}$} & \multirow{3}{*}{$\begin{array}{l}\mathrm{MET}+\mathrm{KTZ}+ \\
\text { mitotane (high- } \\
\text { dose combination } \\
\text { therapy) }\end{array}$} & \multirow[t]{3}{*}{$3000 \mathrm{mg} /$ day (12) } & $\begin{array}{l}\text { Rapid and substantial improvement in the clinical features of CS (e.g. } \\
\text { systolic BP, body weight) in all pts }\end{array}$ \\
\hline & & & $\begin{array}{l}\text { Median UFC excretion and median serum cortisol concentrations } \downarrow \\
\text { rapidly }(24-48 \mathrm{~h} \text { ) from BL }(p<0.01) \text {; UFC excretion remained low to } \\
\text { normal during combination tx }\end{array}$ \\
\hline & & & $\begin{array}{l}\text { All pts underwent pituitary surgery after a median of 5-22 mo. of com- } \\
\text { bination therapy, } 5 \text { of whom were in remission }\end{array}$ \\
\hline
\end{tabular}

$A C T H$ adrenocorticotropic hormone, $B L$ baseline, $B P$ blood pressure, $C D$ Cushing's disease, $C S$ Cushing's syndrome, $E A S$ ectopic ACTH-syndrome, $K T Z$ ketoconazole, $(m) L N S C$ (mean) late-night salivary cortisol, MET metyrapone, mo. month(s), pts patients, $Q o L$ quality of life, TSS transsphenoidal surgery, $t x$ treatment, $(m) U F C$ (mean) urinary free cortisol, $U L N$ upper limit of normal, $w k(s)$ week(s), $\downarrow$ decrease(d)

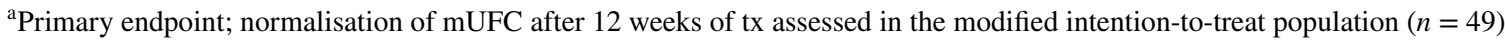

${ }^{\mathrm{b}}$ Median daily dose of $750 \mathrm{mg}$ ( 3 capsules) at days 14, 31, 65 and 82; and $1000 \mathrm{mg}$ (4 capsules) at day 48

fasting plasma insulin, $\mathrm{HbAlc}$, fasting plasma glucose and cholesterol [56].

Results of the 6-month extension of the PROMPT trial demonstrated that metyrapone treatment was associated with a sustained efficacy (Table 2) [58]. At the time of the last assessment of extension (week 36), mUFC normalisation was evident in $49 \%$ of patients who completed the extension $(n=35)$, and a further $23 \%$ of patients had a decrease of mUFC $\geq 50 \%$ from baseline without achieving normalisation. At week 36, 27\% of patients had LNSC normalisation; clinical improvements were also sustained over time (Table 2) [58].

Further support for the long-term efficacy of metyrapone was demonstrated in a subset of patients $(n=38)$ who were treated for $>6$ months in the largest $(n=195)$ retrospective study [treatment duration range, 3 days to 11.6 years] (Tables 3 and 4) [59]. Metyrapone monotherapy was associated with improvements in all monitoring tests during treatment and at the last review on treatment (Tables 3 and 4); patients on a block-and-replace regimen were more likely to achieve mean cortisol day-curve (CDC) levels $<150 \mathrm{nmol} / \mathrm{L}$ [59]. Improvements in cortisol levels were also evident amongst $81 \%$ and $89 \%$ of patients who had CDC or 9 a.m. cortisol levels monitored but did not achieve the normalised cortisol target or biochemical targets, respectively [59]. Improvements in biochemical markers were evident amongst patients treated with metyrapone monotherapy before surgery, monotherapy as secondary treatment, when used as long-term treatment and combination treatment (Tables 3 and 4).
The efficacy of metyrapone as presurgical treatment has been demonstrated in a number of studies (Tables 2 and 3 ). One example is a retrospective study of the effect of the preoperative effects of steroidogenesis inhibitors (metyrapone and/or ketoconazole) in 62 patients with Cushing's syndrome (Table 3). Patients were classified based on biochemical (UFC within normal range of 50-280 nmol/24 h) and clinical control [defined as the disappearance or significant improvement of signs and symptoms of Cushing's syndrome as described at the start of treatment, and control of comorbidities (hypertension and diabetes that were present when treatment was started)] of hypercortisolism at the end of treatment (i.e. day of surgery) [60]. Patients who were controlled or partially controlled underwent surgery 4-6 weeks after UFC normalisation, whereas patients who were not controlled with medication underwent planned surgery after several unsuccessful titrations. The majority (52\%) of patients achieved normalisation of UFC [60]. Amongst patients treated with metyrapone alone, UFC normalisation was achieved in $57 \%$ of patients, of whom $46 \%$ also achieved clinical control. UFC normalisation was achieved by $45 \%$ of patients treated with metyrapone and ketoconazole combination therapy. Long-term post-operative remission was achieved by the majority (76\%) of patients with Cushing's disease who underwent transsphenoidal surgery (Table 3).

Presurgical medical cortisol suppression with metyrapone in Cushing's disease was also associated with suppression of postoperative cortisol concentrations and increased rates of long-term remission (Table 3) [61]. Moreover, adequate pretreatment and postoperative serum cortisol demonstrated 
a positive relationship $(p=0.02)$ to long-term remission in a univariate logistic regression analysis [61].

Metyrapone demonstrated efficacy in the management of acute psychiatric states which may occur in Cushing's syndrome. When administered to control excessive cortisol production in 32 patients with psychiatric manifestations associated with Cushing's syndrome, oral metyrapone $(0.5-6.0 \mathrm{~g} /$ day $)$ was associated with resolution of these manifestations in the majority of those severely or markedly affected [15]. When used preoperatively in a 56-year old patient with Cushing's syndrome, right adrenal adenoma and major depression [score of 27 on the 17-item Hamilton Depression Rating Scale (HAM-D)], metyrapone (1.5 g/day) was associated with an improvement of the depressive state (score of 7 on the HAM-D rating scale) [62].

The efficacy of metyrapone was also demonstrated in ACTH-independent macronodular adrenocortical hyperplasia (AIMAH) [currently known as primary bilateral macronodular adrenocortical hyperplasia [63]], a rare form of Cushing's syndrome that usually affects the elderly, for whom standard therapy (i.e. bilateral adrenalectomy) is contraindicated. In a case report, metyrapone (500-750 $\mathrm{mg} /$ day; $2-3$ capsules) treatment was effective in treating a patient with AIMAH for several months, with a reduction of cortisol levels to the normal range, as well as amelioration of hypertension and diabetes mellitus [64]. Furthermore, long-term treatment with metyrapone (1000 mg; 4 capsules) also improved severe hypercortisolaemia in a patient with AIMAH (7 years) [65]. Earlier reports of long-term (3-4 years) metyrapone therapy in patients with bilateral adrenal hyperplasia because of ACTH-dependent Cushing's syndrome and McCune-Albright syndrome also demonstrated an improvement in hypercortisolaemia $[9,66]$.

Patients with adrenal incidentalomas (AI) with mild autonomous cortisol secretion (ACS) [also known as subclinical Cushing's syndrome] have abnormal circadian cortisol rhythm as well as elevated serum interleukin-6 (IL-6) levels (cardiovascular risk marker), as shown in a phase $1 / 2 \mathrm{a}$ prospective study [67]. Serum cortisol levels (6-10 p.m. and 10 p.m. -2 a.m.) in these patients $(n=6)$ were significantly $(p<0.05)$ higher than in patients with AI without ACS $(n=6)$ or healthy volunteers $(n=8)$. In patients with AI/ ACS, administration of metyrapone $500 \mathrm{mg}$ (2 capsules) at 6 p.m. and $250 \mathrm{mg}$ (1 capsule) at 10 p.m. was associated with a reset of cortisol rhythm and salivary cortisone rhythm (to normal physiological levels) as indicated by normalisation of cortisol exposure and area under the concentration-time curve of salivary cortisol; serum IL-6 levels were also normalised to levels similar to those observed in the two control groups [67].

\section{What is the safety and tolerability profile of metyrapone?}

Metyrapone is generally well tolerated when used in the treatment of patients with Cushing's syndrome, based on the available evidence. The most commonly reported adverse events with metyrapone are gastrointestinal disturbances, which can be minimised by taking metyrapone with milk or after meals [6]; adverse events most commonly occurred when initiating treatment or increasing dosage [56]. For example, in the long-term, metyrapone was generally well tolerated, with adverse events reported in $25 \%$ of patients, most commonly gastrointestinal upset $(23 \%)$ and hypoadrenalism (7\%, with symptoms of dizziness, hypotension, with biochemical confirmation); adverse events were usually transient and typically occurred following metyrapone initiation (within 2 weeks) or dose increase [59].

Central nervous system adverse events (including dizziness, sedation, headache) may occur with metyrapone treatment [6]. For example, dizziness was reported in 3 patients in the real-life study $(n=31)$ [5]. Given that dizziness and sedation can occur with metyrapone, patients should not drive or operate machinery until these effects have passed [6].

Adrenal insufficiency is the main risk of metyrapone treatment, but is manageable [6]. There were no occurrences of adrenal insufficiency in the real-life study [5]. In the largest case series of 195 patients, hypoadrenalism occurred in 7\% of patients [59]. Hypoadrenalism was managed by the addition of a glucocorticoid (i.e. changing the regimen to a block-and-replace) or by temporary cover with a glucocorticoid and simultaneous reduction of metyrapone dose. Safety results of the 12-week interim analysis of the PROMPT study indicate that reversible adrenal insufficiency was reported in $12 \%$ of patients during the titration period $[56,57]$ and in no patients during the 6-month extension period [58]. Episodes of adrenal insufficiency were managed either by reduction of metyrapone dose or temporary withdrawal with or without the temporary addition of glucocorticoid [58].

Accumulation of the adrenal steroid precursor, 11-desoxycorticosterone, with mineralocorticoid activity may occur, leading to hypertension, oedema, or hypokalaemia $[4,6]$. Monitoring of blood pressure and serum potassium is advised and corrective treatment may be needed. In the PROMPT study, peripheral oedema occurred in $14 \%$ of patients (all before week 12), hypokalaemia in $8 \%$ of patients (all before week 12) and hypertension in $14 \%$ of patients (with $10 \%$ before week 12 ); all events were of mild or moderate in severity, and were resolved for the majority of patients under treatment [58]. 
Table 3 Summary of key $(n>6)$ retrospective studies demonstrating the efficacy of metyrapone in the treatment of Cushing's syndrome

Study details

Key efficacy results

No. of pts Tx $\quad \begin{aligned} & \text { Median MET dosage } \\ & \text { (no. of capsules) }\end{aligned}$

(no. of capsules)

\begin{tabular}{|c|c|c|}
\hline \multicolumn{3}{|c|}{ Valassi et al. (2012) [60] } \\
\hline $\begin{array}{l}62 \text { (52 with CD, } 9 \\
\text { ACTH-independ- } \\
\text { ent CS and } 1 \text { with } \\
\text { ACTH-dependent } \\
\text { CS) }\end{array}$ & $\begin{array}{l}\mathrm{MET} \pm \mathrm{KTZ} \text { as } \\
\text { preoperative tx } \\
\text { in previoustly } \\
\text { untreated pts }\end{array}$ & $\begin{array}{l}\text { Initial daily dose } \\
\text { range } 750-1000 \mathrm{mg} \\
\text { (3-4) and was } \uparrow \text { by } \\
250 \mathrm{mg}(1) \text { at a time } \\
\text { if necessary }\end{array}$ \\
\hline \multicolumn{3}{|c|}{ van den Bosch et al. (2014) [61] } \\
\hline 33 (all with CD) & $\begin{array}{l}\text { MET }(n=22), \mathrm{KTZ} \\
(n=10) \text { or MET }+ \\
\text { KTZ }(n=1) \text { prior } \\
\text { to TSS }\end{array}$ & $\begin{array}{l}\text { Range } 1000- \\
6000 \mathrm{mg} / \text { day (4-24) } \\
\text { [monotherapy], and } \\
1000 \mathrm{mg} / \text { day (4) in } \\
\text { the pt who received } \\
\text { MET+KTZ }\end{array}$ \\
\hline
\end{tabular}

\begin{tabular}{|c|c|c|}
\hline \multicolumn{3}{|c|}{ Corcuff et al. (2015) [69] } \\
\hline $\begin{array}{l}14 \text { with EAS and } 8 \\
\text { with ACC, with } \\
\text { severe hypercorti- } \\
\text { solism }\end{array}$ & $\mathrm{MET}+\mathrm{KTZ}$ & $\begin{array}{l}2125 \mathrm{mg} / \text { day (equiva- } \\
\text { lent to } 8.5 \text { capsules) } \\
\text { [median starting } \\
\text { dosage] }\end{array}$ \\
\hline \multicolumn{3}{|c|}{ Jeffcoate et al. (1977) [14] } \\
\hline $\begin{array}{l}13 \text { with pituitary- } \\
\text { dependent bilateral } \\
\text { adrenal hyperplasia } \\
\text { (CD) }\end{array}$ & $\begin{array}{l}\text { MET + course of } \\
\text { external pituitary } \\
\text { irradiation (long- } \\
\text { term management) }\end{array}$ & $\begin{array}{l}\text { Range } 250 \mathrm{mg}(1) \\
\text { twice daily to } \\
1000 \mathrm{mg} \text { (4) QID }\end{array}$ \\
\hline
\end{tabular}

$32 \%$ of pts were controlled, $19 \%$ partially controlled and $48 \%$ not controlled

Cortisol escape in 3 pts with CD after a median of 6.6 mo.

In the long-term (median follow up 108 mo.), 38/50 pts with $\mathrm{CD}$ who underwent TSS achieved remission, 12/38 pts in remission relapsed

van den Bosch et al. (2014) [61]

$(n=10)$ or MET +

16 pts were adequately pretreated (10 pts were treated with MET, 1 with $\mathrm{MET}+\mathrm{KTZ}$ and 5 with KTZ)

Borderline adequate pre-tx in 7 pts ( 6 treated with MET); inadequate pre-tx in 6 pts ( 3 each with MET or KTZ) and unknown adequacy in 4 pts (3 treated with MET)

Long-term remission achieved in $8 / 10$ pts who were adequately pretreated with MET and $1 \mathrm{pt}$ with MET+KTZ; and in 3/6 pts who had borderline adequate pre-tx with MET; and 1/3 pts with unknown adequacy with MET

Rates of very low postoperative cortisol concentrations ( $81 \%$ vs. $15 \%)$ and long-term remission $(81 \%$ vs. $38 \%)$ were higher $(p<0.05)$ in patients who were adequately pretreated than those who had inadequate pre-tx prior to primary surgery

Median $\downarrow$ in UFC of $96 \%$ and $94 \%$ in pts with EAS and ACC after 1 mo. of tx; a similar trend for midnight plasma cortisol

Normalisation of UFC in $50 \%$ and $75 \%$ of pts with EAS and ACC after 1 wk of tx, and in $73 \%$ and $86 \%$ of pts after 1 mo.

Jeffcoate et al. (1977) [14]

with pituitary- MET + course of external pituitary (CD) term management)
Rapid and sustained improvement of disease clinical features (facial plethora, muscle weakness and pronounced psychiatric stigmata)

Abnormal glucose tolerance (5/7 pts) and hypertension (7/12 pts) corrected in the majority of pts

Plasma ACTH concentrations $\uparrow$ in all pts, but did not overcome the adrenal blockade induced by MET

Daniel et al. (2015) [59]

$\begin{array}{ll}195 \text { with CS (115 } & \text { MET as monotherapy } \\ \text { with CD, 37 with } & (n=164) \text { [presur- } \\ \text { EAS, 10 with } & \text { gery }(n=124), \\ \text { adrenocortical } & \text { as secondary tx } \\ \text { carcinoma, 30 with } & (n=21) \text {, as long- } \\ \text { adrenal adenoma, } 3 & \text { term tx }(n=38) \text { ] } \\ \text { with ACTH-inde- } & \text { or as combination } \\ \text { pendent adrenal } & \text { tx (mainly KTZ or } \\ \text { hyperplasia) } & \text { mitotane; } n=29)\end{array}$

\section{See Table 4}

$\downarrow$ mean CDC, 9 a.m. serum cortisol [both $p<0.0001$ during tx (i.e. the mean of all tests performed in all pts during tx) and at the last review on tx vs. pre-tx values], UFC and UFC:ULN ratio for the assay used (both $p<0.05$ at the last review on $\mathrm{tx}$ ) with MET monotherapy or as presurgery tx

As secondary tx, improved mean CDC and 9 a.m. serum cortisol (both $p$ $\leq 0.002$ during tx and at the last review on tx vs. pre-tx values)

Long-term (MET for $>6$ mo.) MET improved mean CDC (numerical improvements; $p>0.05)$ and 9 a.m. serum cortisol $(p<0.0001)$ during $\mathrm{tx}$ and at the last review on $\mathrm{tx}$

In pts treated with dose titration (81\%) and block-and-replace regimen (19\%), there were no significant differences in the mean 9am serum cortisol levels between the two groups during tx or at the last review

Mean CDC and 9 a.m. serum cortisol both improved with combination tx (both $p \leq 0.003$ during tx and at the last review on tx vs. pre-tx values) 
Table 3 (continued)

Study details

\begin{tabular}{lll}
\hline No. of pts & Tx & $\begin{array}{l}\text { Median MET dosage } \\
\text { (no. of capsules) }\end{array}$
\end{tabular}

Key efficacy results

\section{1 with CS (57 with $\mathrm{CD}, 10$ with adrenocortical adenoma, 6 with adrenocortical carcinoma and 18 with EAS)}

Verhelst et al. (1991) [70]
MET (short- and Short-term: $2250 \mathrm{mg} /$ long-term manage- day (9); median ment)

MET dose/day in pts with adrenocortical adenoma and adrenocortical carcinoma $=1750 \mathrm{mg} \mathrm{(7)}$ and in pts with EAS $=4000 \mathrm{mg}(16)$
Test dose (750 mg; 3 capsules) $\downarrow$ serum cortisol levels from baseline in all pts within $2 \mathrm{~h}$, with reductions from baseline sustained at $4 \mathrm{~h}^{\mathrm{a}}$; serum 11-desoxycortisol levels $\uparrow$ in all pts, plasma ACTH $\uparrow$ in pts with $\mathrm{CD}$ and EAS

Short-term (1-16 wks) MET before definitive therapy, $\downarrow$ mean cortisol levels to target range $(<400 \mathrm{nmol} / \mathrm{L})$ in $75 \%$ of pts with $\mathrm{CD}(n=53)$

Control of hypercortisolaemia achieved in $83 \%$ of pts with CD on longterm MET who had pituitary irradiation $(n=24)$

MET $\downarrow$ mean cortisol levels to target range in $81 \%$ of pts with adrenocortical adenoma and adrenocortical carcinoma

MET $\downarrow$ mean cortisol level to target range in $70 \%$ of pts with EAS

\begin{tabular}{l} 
Thorén et al. (1985) [71] \\
\hline 15 with endogenous MET and/or AG $500-3000 \mathrm{mg} /$ day \\
CS (11 with CD, 1 \\
each with adrenal \\
adenoma and \\
ACC, 2 with EAS)
\end{tabular}

MET $\downarrow$ urinary cortisol secretion by a mean of $54 \%$ after $1 \mathrm{wk}$ in 7 pts (all with CD); clinical improvements in 7/9 pts

MET induced remission in $1 \mathrm{pt}$ with cortisol-producing adenoma [72], and $\downarrow$ cortisol production by $>50 \%$ in 1 pt with ACC
Combined MET+AG did not further $\downarrow$ cortisol secretion in 2 pts with $\mathrm{CD}$

Combination tx $\downarrow$ cortisol secretion in 1 pt with adrenal adenoma and 2 pts with EAS, but there were no obvious clinical improvements

Child et al. (1976) [73]

$\begin{array}{ccl}18 \text { with CS (16 with } & \text { MET, AG, DEX, FC } & \text { Preliminary regimen: } \\ \text { CD, } 1 \text { with EAS, } & 2000-4200 \mathrm{mg} / \\ 1 \text { with primary } & \text { day }(8-17) ; \text { short- } \\ \text { adrenal adenoma) } & \text { term and long-term } \\ & \text { regimens: } 2000 \mathrm{mg} / \\ & \text { day }(8)\end{array}$

Preliminary regimen ( $2 \mathrm{wks})$ : MET normalised plasma and UFC in all 10 pts with available measurements by day 5; normalisation sustained in most pts (except 1 pt with apparent cortisol escape on day 11)

Short-term regimen ( $2 \mathrm{wks}$ ): MET normalised plasma and UFC by day 1 and day 3 in all 5 pts and no evidence of cortisol escape by day 15

Long-term regimen (26 days-1 year): MET normalised plasma cortisol and UFC, with normalisation sustained during tx in all 3 pts (except a single elevated UFC due to a missed dose on the previous day)

General improvements in clinical outcomes

$A C C$ adrenal carcinoma, $A C T H$ adrenocorticotropic hormone, $A G$ aminoglutethimide, $C D$ Cushing's disease, $C D C$ cortisol day-curve, $C S$ Cushing's syndrome, $D E X$ dexamethasone, $E A S$ ectopic ACTH-syndrome, $F C$ fludrocortisone, KTZ ketoconazole, $M E T$ metyrapone, $m o$. month(s), $p t(s)$ patient(s), QID four times a day, TSS transsphenoidal surgery, $t x$ treatment, $U F C$ urinary free cortisol, $U L N$ upper limit of normal, $w k(s)$ week(s), $\downarrow$ decrease(d), $\uparrow$ increased

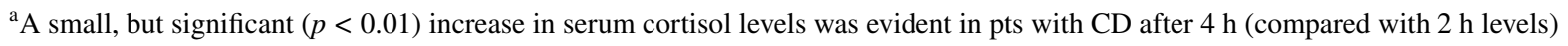

An increase of blood pressure levels occurred in two normotensive patients receiving metyrapone treatment in the real-life study, both of whom were controlled with medical monotherapy; amongst hypertensive patients $(n=24)$, uptitration of antihypertensive treatment was required in five patients, while four patients stopped their antihypertensive medication during the study [5]. Overall, there was no increase of systolic or diastolic blood pressure.

Other potential adverse events during long-term treatment with metyrapone, include new onset or worsening of hirsutism or acne, as a result of androgenic precursors accumulation (because of cortisol synthesis blockade) [4]; these adverse events have not been consistently reported [hirsutism was not reported and worsening acne occurred in one patient during treatment in the largest retrospective study [59]; hirsutism occurred in five female patients (with alopecia in one patient, leading to discontinuation of metyrapone) in the real-life study [5]; hirsutism occurred in three female patients (leading to treatment discontinuation in one case) during the 6-month extension of PROMPT [58]].

The adverse events of hypertension, oedema, hypokalaemia and hyperandrogenism can be controlled by adding spironolactone, which blocks the androgen and mineralocorticoid receptors [74]. 


\begin{tabular}{|c|c|c|c|c|c|}
\hline Trial description & $\begin{array}{l}\text { Monotherapy } \\
(n=164)^{\mathrm{b}}\end{array}$ & $\begin{array}{l}\text { Before surgery } \\
(n=124)^{\mathrm{c}}\end{array}$ & $\begin{array}{l}\text { Secondary therapy } \\
(n=21)^{\mathrm{d}}\end{array}$ & $\begin{array}{l}\text { Long-term treatment } \\
(n=38)^{\mathrm{e}}\end{array}$ & $\begin{array}{l}\text { Combination } \\
\text { therapy } \\
(n=29)^{\mathrm{f}}\end{array}$ \\
\hline \multicolumn{6}{|c|}{ Control $^{\mathrm{g}}(\% \mathrm{pts})$ at the last review based on } \\
\hline $\mathrm{CDC}$ & 55 & 50 & 76 & 72 & 47 \\
\hline UFC & 43 & 35 & - & 64 & - \\
\hline $\begin{array}{l}9 \text { a.m. serum cortisol } \\
\text { levels }<331 \mathrm{nmol} / \mathrm{L}\end{array}$ & 46 & 40 & 78 & 77 & 52 \\
\hline $\begin{array}{l}9 \text { a.m. cortisol levels }< \\
\text { ULN or }<600 \mathrm{nmol} / \mathrm{L}^{\mathrm{h}}\end{array}$ & 76 & 72 & 94 & 94 & 75 \\
\hline
\end{tabular}

$C D C$ cortisol day-curve, pts patients, UFC urinary free cortisol, $U L N$ upper limit of normal

${ }^{a}$ Monitoring data during metyrapone therapy available for $193 \mathrm{pts}$

b91 pts were monitored with CDCs during treatment, 37 pts had UFC monitored and 123 pts had 9 a.m. serum cortisol levels monitored

${ }^{\mathrm{c}} 70$ pts were monitored with CDCs during treatment, 25 pts had UFC monitored and 82 pts had 9 a.m. serum cortisol levels monitored

${ }^{\mathrm{d}} 12$ pts were monitored with CDCs during treatment and 17 pts had 9 a.m. serum cortisol levels monitored

e 25 pts were monitored with CDCs during treatment, 14 pts had UFC monitored and 31 pts had 9 a.m. serum cortisol levels monitored

${ }^{\mathrm{f}} 17$ pts were monitored with CDCs during treatment and 20 pts had 9 a.m. serum cortisol levels monitored

${ }^{\mathrm{g}}$ Eucortisolaemia defined as a mean CDC value of 150-300 nmol/L, a UFC level < the ULN for the assay used or a 9 a.m. serum cortisol within target

${ }^{\mathrm{h}}<$ the ULN for the assay used, or $<600 \mathrm{nmol} / \mathrm{L}(21.7 \mu \mathrm{g} / \mathrm{dL})$ if the ULN was higher than this value

\section{What is the current clinical position of metyrapone in Cushing's syndrome?}

Metyrapone is a useful treatment option in the management of Cushing's syndrome. Evidence for the efficacy and safety of metyrapone in the treatment of Cushing's syndrome is derived from more than six decades of use in clinical practice [44], as well as results of studies (including in the long term) that demonstrate that metyrapone has a rapid onset of action, is effective and generally well tolerated. Metyrapone treatment was associated with control of hypercortisolism (assessed using UFC and/or LNSC), as well as improvements in the clinical and/or biochemical features and cortisol-related comorbidities of the disease. The efficacy of metyrapone was demonstrated across all aetiologies of the disease and across a range of clinical settings. Genetic differences in steroidogenic enzymes may contribute to interindividual variability in the responses to adrenal-blocking agents in Cushing's syndrome [75]. A common polymorphism in the CYP17A1 gene was found to influence the therapeutic response to steroidogenesis inhibitors (metyrapone and/or ketoconazole) in patients with Cushing's syndrome [75]. Gastrointestinal disturbances were the most commonly reported adverse events with metyrapone treatment. Of note, when considering the tolerability profile of metyrapone in patients with Cushing's syndrome, it may be difficult to establish whether adverse events are related to treatment or to the natural history of Cushing's syndrome.
The current Endocrine Society Clinical Practice Guidelines for the treatment of Cushing's syndrome include recommendations for the use of steroidogenesis inhibitors (including metyrapone) as second-line treatment after transsphenoidal selective adenomectomy in patients with Cushing's disease (with or without radiation therapy/radiosurgery), as primary treatment of EAS in patients with occult or metastatic EAS, and as adjunctive treatment to reduce cortisol levels in adrenocortical carcinoma [4]. Clinical normalisation (using cortisol levels as a proxy endpoint) is the goal of medical therapy, and can be achieved with a block-and-replace regimen or with a normalisation strategy to achieve eucortisolism. The choice of medical therapy should be driven by efficacy, individual patient factors and cost. The guidelines also acknowledge the role of combination therapy with metyrapone plus ketoconazole to enhance the control of severe hypercotisolaemia [4].

The cortisol circadian rhythm is frequently disrupted in patients with Cushing's syndrome [67]. UFC is commonly used in studies and clinical practice to monitor the response to cortisol-lowering drugs in patients with Cushing's disease; however; relying solely on UFC cannot provide information on circadian fluctuations of cortisol or midnight cortisol levels [76]. LNSC, like UFC, has an established role in screening for hypercortisolism and identifying recurrence after surgery; furthermore, it has been shown that LNSC plays a role in the morbidity of dysregulated cortisol secretion $[77,78]$. Findings of an exploratory analysis evaluating LNSC during a phase III study of medical treatment in 
Cushing's disease indicate that better clinical outcomes are evident for patients in whom mUFC and mLNSC measurements are controlled; the use of mUFC and mLNSC can offer a comprehensive assessment of response to treatment in patients with Cushing's disease [76]. Interestingly, results of a prospective case study indicate that multiple salivary cortisol measurements may be a useful tool to visualise the diurnal cortisol rhythm and to optimise the dose and timing of metyrapone during treatment in patients with Cushing's syndrome [79]. Metyrapone contributes to restoring the circadian rhythm $[5,56,67,79]$ and lowers the nocturnal cortisol exposure, while leaving the cortisol levels unaltered throughout the rest of the day in subclinical Cushing's syndrome. Improvement/control of elevated cortisol levels is also required during the rest of the day in patients with Cushing's syndrome; the rapid onset of action of metyrapone together with its short duration of action, allows the timing and dosage to be fine-tuned, and may enable improvement or restoration of normal circadian rhythm.

Acknowledgements The manuscript was reviewed by: A. Singh, All India Institute of Medical Sciences Raipur, Raipur, Chhattisgarh, India; S. M. Webb, Department of Endocrinology/Medicine, Hospital Sant Pau, Universitat Autònoma de Barcelona, CIBERER group747, Barcelona, Spain. During the peer review process, HRA Pharma Rare Diseases, the marketing-authorization holder of metyrapone, was also offered an opportunity to provide a scientific accuracy review of their data. Changes resulting from comments received were made on the basis of scientific and editorial merit.

\section{Declarations}

Funding The preparation of this review was not supported by any external funding.

Authorship and conflicts of interest Z. T. Al-Salama is a salaried employee of Adis International Limited/Springer Nature and an editor of Drugs \& Therapy Perspectives. She was not involved in any publishing decisions for this manuscript and declares no relevant conflicts of interest. All authors contributed to the review and are responsible for the article content.

Ethics approval, Consent to participate, Consent for publication, Availability of data and material, Code availability Not applicable.

Open Access This article is licensed under a Creative Commons Attribution-NonCommercial 4.0 International License, which permits any non-commercial use, sharing, adaptation, distribution and reproduction in any medium or format, as long as you give appropriate credit to the original author(s) and the source, provide a link to the Creative Commons licence, and indicate if changes were made. The images or other third party material in this article are included in the article's Creative Commons licence, unless indicated otherwise in a credit line to the material. If material is not included in the article's Creative Commons licence and your intended use is not permitted by statutory regulation or exceeds the permitted use, you will need to obtain permission directly from the copyright holder. To view a copy of this licence, visit http://creativecommons.org/licenses/by-nc/4.0/.

\section{References}

1. Igaz P, Tömböl Z, Szabó PM, et al. Steroid biosynthesis inhibitors in the therapy of hypercortisolism: theory and practice. Curr Med Chem. 2008;15(26):2734-47.

2. Hakami OA, Ahmed S, Karavitaki N. Epidemiology and mortality of Cushing's syndrome. Best Pract Res Clin Endocrinol Metab. 2021;35(1):101521.

3. Lacroix A, Feelders RA, Stratakis CA, et al. Cushing's syndrome. Lancet. 2015;386(9996):913-27.

4. Nieman LK, Biller BM, Findling JW, et al. Treatment of Cushing's syndrome: an endocrine society clinical practice guideline. J Clin Endocrinol Metab. 2015;100(8):2807-31.

5. Ceccato F, Zilio M, Barbot M, et al. Metyrapone treatment in Cushing's syndrome: a real-life study. Endocrine. 2018;62(3):701-11.

6. HRA Pharma Rare Diseases. Metopirone ${ }^{\circledR}$ (metyrapone): summary of product characteristics. 2020. http://www.hpra.ie/img/uploa ded/swedocuments/Licence_PA22888-001-001_2508202012 5137.pdf. Accessed 28 June 2021.

7. HRA Pharma Rare Diseases. Metopirone ${ }^{\circledR}$ (metyrapone) capsules: US prescribing information. 2020. https://www.accessdata.fda. gov/drugsatfda_docs/label/2020/012911s036lbl.pdf. Accessed 28 June 2021.

8. Comi RJ, Gorden P. Long-term medical treatment of ectopic ACTH syndrome. South Med J. 1998;91(11):1014-8.

9. Dickstein G, Lahav M, Shen-Orr Z, et al. Primary therapy for Cushing's disease with metyrapone. JAMA. 1986;255(9):1167-9.

10. Gartner LA, Voorhess ML. Adrenocorticotropic hormone-producing thymic carcinoid in a teenager. Cancer. 1993;71(1):106-11.

11. Gillis D, Rösler A, Hannon TS, et al. Prolonged remission of severe Cushing syndrome without adrenalectomy in an infant with McCune-Albright syndrome. J Pediatr. 2008;152(6):882-4.e4.

12. Halioui-Louhaichi S, Dridi Y, Azzabi O, et al. Recovery of Cushing syndrome revealing McCune-Albright syndrome. Arch Pediatr. 2016;23(1):61-5.

13. Hána V, Dokoupilová M, Marek J, et al. Recurrent ACTHindependent Cushing's syndrome in multiple pregnancies and its treatment with metyrapone. Clin Endocrinol (Oxf). 2001;54(2):277-81.

14. Jeffcoate WJ, Rees LH, Tomlin S, et al. Metyrapone in long-term management of Cushing's disease. Br Med J. 1977;2(6081):215-7.

15. Jeffcoate WJ, Silverstone JT, Edwards CR, et al. Psychiatric manifestations of Cushing's syndrome: response to lowering of plasma cortisol. Q J Med. 1979;48(191):465-72.

16. Littley MD, Shalet SM, Beardwell CG, et al. Long-term follow-up of low-dose external pituitary irradiation for Cushing's disease. Clin Endocrinol (Oxf). 1990;33(4):445-55.

17. Lourenço R, Dias P, Gouveia R, et al. Neonatal McCune-Albright syndrome with systemic involvement: a case report. J Med Case Rep. 2015;9:189.

18. Luca PD, Oren A, Somers GR, et al. The search for ectopic ACTH production in a 9-year-old boy. J Pediatr Endocrinol Metab. 2013;26(7-8):781-3.

19. Rydzewska M, Krawczuk-Rybak M, Zajkowska A, et al. Cushing's syndrome in infancy due to ectopic ACTH secretion by a sacro-coccygeal teratoma. J Pediatr Endocrinol Metab. 2017;30(4):475-8.

20. Storr HL, Mitchell H, Swords FM, et al. Clinical features, diagnosis, treatment and molecular studies in paediatric Cushing's syndrome due to primary nodular adrenocortical hyperplasia. Clin Endocrinol (Oxf). 2004;61(5):553-9.

21. Verbeeten K, Hadjiyannakis S, Cameron M, et al. Rectal metyrapone for treatment of hypercortisolism in an infant 
with McCune-Albright syndrome. J Pediatr Pharmacol Ther. 2017;22(3):233-6.

22. Vieira H, Brain C. Cushing syndrome associated with an adrenal tumour. BMJ Case Rep. 2012. https://doi.org/10.1136/ bcr-2012-006685.

23. Wojcik M, Kalicka-Kasperczyk A, Luszawska-Kutrzeba T, et al. The first description of metyrapone use in severe Cushing Syndrome due to ectopic ACTH secretion in an infant with immature sacrococcygeal teratoma. Case report. Neuro Endocrinol Lett. 2015;36(7):653-5.

24. Beardwell CG, Adamson AR, Shalet SM. Prolonged remission in florid Cushing's syndrome following metyrapone treatment. Clin Endocrinol (Oxf). 1981;14(5):485-92.

25. Doi M, Sugiyama $\mathrm{T}$, Izumiyama $\mathrm{H}$, et al. Clinical features and management of ectopic ACTH syndrome at a single institute in Japan. Endocr J. 2010;57(12):1061-9.

26. Donckier J, Burrin JM, Ramsay ID, et al. Successful control of Cushing's disease in the elderly with long term metyrapone. Postgrad Med J. 1986;62(730):727-30.

27. Hotham NJ, Ilett KF, Hackett LP, et al. Transfer of metyrapone and its metabolite, rac-metyrapol, into breast milk. J Hum Lact. 2009;25(4):451-4.

28. Achong N, D'Emden M, Fagermo N, et al. Pregnancy-induced Cushing's syndrome in recurrent pregnancies: case report and literature review. Aust N Z J Obstet Gynaecol. 2012;52(1):96-100.

29. Blanco C, Maqueda E, Rubio JA, et al. Cushing's syndrome during pregnancy secondary to adrenal adenoma: metyrapone treatment and laparoscopic adrenalectomy. J Endocrinol Investig. 2006;29(2):164-7.

30. Kamenický P, Droumaguet C, Salenave S, et al. Mitotane, metyrapone, and ketoconazole combination therapy as an alternative to rescue adrenalectomy for severe ACTH-dependent Cushing's syndrome. J Clin Endocrinol Metab. 2011;96(9):2796-804.

31. Lim WH, Torpy DJ, Jeffries WS. The medical management of Cushing's syndrome during pregnancy. Eur J Obstet Gynecol Reprod Biol. 2013;168(1):1-6.

32. Lindsay JR, Jonklaas J, Oldfield EH, et al. Cushing's syndrome during pregnancy: personal experience and review of the literature. J Clin Endocrinol Metab. 2005;90(5):3077-83.

33. Zieleniewski W, Michalak R. A successful case of pregnancy in a woman with ACTH-independent Cushing's syndrome treated with ketoconazole and metyrapone. Gynecol Endocrinol. 2017;33(5):349-52.

34. Diri H, Bayram F, Simsek Y, et al. A pregnant woman who underwent laparoscopic adrenalectomy due to Cushing's syndrome. Case Rep Endocrinol. 2014;2014:283458.

35. Klibanski A, Stephen AE, Greene MF, et al. Case records of the Massachusetts General Hospital. Case 36-2006. A 35-yearold pregnant woman with new hypertension. N Engl J Med. 2006;355(21):2237-45.

36. Cabezon C, Bruno OD, Cohen M, et al. Twin pregnancy in a patient with Cushing's disease. Fertil Steril. 1999;72(2):371-2.

37. Close CF, Mann MC, Watts JF, et al. ACTH-independent Cushing's syndrome in pregnancy with spontaneous resolution after delivery: control of the hypercortisolism with metyrapone. Clin Endocrinol (Oxf). 1993;39(3):375-9.

38. Connell JM, Cordiner J, Davies DL, et al. Pregnancy complicated by Cushing's syndrome: potential hazard of metyrapone therapy. Case report Br J Obstet Gynaecol. 1985;92(11):1192-5.

39. Gormley MJ, Hadden DR, Kennedy TL, et al. Cushing's syndrome in pregnancy - treatment with metyrapone. Clin Endocrinol (Oxf). 1982;16(3):283-93.

40. Wallace C, Toth EL, Lewanczuk RZ, et al. Pregnancy-induced Cushing's syndrome in multiple pregnancies. J Clin Endocrinol Metab. 1996;81(1):15-21.
41. Kasperlik-Zaluska AA, Szczupacka I, Leszczynska-Bystrzanowska J, et al. Pregnancy-dependent Cushing's syndrome in three pregnancies. BJOG. 2000;107(6):810-2.

42. Galinsky RE, Nelson EB, Rollins DE. Pharmacokinetic consequences and toxicologic implications of metyrapone-induced alterations of acetaminophen elimination in man. Eur J Clin Pharmacol. 1987;33(4):391-6.

43. Rigel DF, Fu F, Beil M, et al. Pharmacodynamic and pharmacokinetic characterization of the aldosterone synthase inhibitor FAD286 in two rodent models of hyperaldosteronism: comparison with the 11 beta-hydroxylase inhibitor metyrapone. J Pharmacol Exp Ther. 2010;334(1):232-43.

44. Daniel E, Newell-Price JD. Therapy of endocrine disease: steroidogenesis enzyme inhibitors in Cushing's syndrome. Eur J Endocrinol. 2015;172(6):R263-80.

45. Creemers SG, Feelders RA, de Jong FH, et al. Osilodrostat is a potential novel steroidogenesis inhibitor for the treatment of Cushing syndrome: an in vitro study. J Clin Endocrinol Metab. 2019;104(8):3437-49.

46. Sampath-Kumar R, Yu M, Khalil MW, et al. Metyrapone is a competitive inhibitor of 11 beta-hydroxysteroid dehydrogenase type 1 reductase. J Steroid Biochem Mol Biol. 1997;62(2-3):195-9.

47. Blichert-Toft M, Folke K, Nielsen ML. Effects of metyrapone and corticotropin infusion on cortisol disappearance rate in man. J Clin Endocrinol Metab. 1972;35(1):59-62.

48. Levin J, Zumoff B, Fukushima DK. Extraadrenal effects of metyrapone in man. J Clin Endocrinol Metab. 1978;47(4):845-9.

49. Schöneshöfer M, Schefzig B, Arabin S. Short-term kinetics of serum adrenal steroids and plasma ACTH after a single dose of metyrapone in man. J Endocrinol Invest. 1980;3(3):229-36.

50. Sprunt JG, Browning MC, Hannah DM. Some aspects of the pharmacology of metyrapone. Proc R Soc Med. 1967;60(9):908-9.

51. Halsall DJ, Gurnell M. Comparison of serum cortisol measurement by immunoassay and liquid chromatography-tandem mass spectrometry in patients receiving the $11 \beta$-hydroxylase inhibitor metyrapone. Ann Clin Biochem. 2012;49(2):204.

52. Monaghan PJ, Owen LJ, Trainer PJ, et al. Comparison of serum cortisol measurement by immunoassay and liquid chromatography-tandem mass spectrometry in patients receiving the 11 beta-hydroxylase inhibitor metyrapone. Ann Clin Biochem. 2011;48(5):441-6.

53. Owen LJ, Halsall DJ, Keevil BG. Cortisol measurement in patients receiving metyrapone therapy. Ann Clin Biochem. 2010;47(6):573-5.

54. European Medicines Agency. Ketoconazole HRA: public assessment report. 2015. https://www.ema.europa.eu/en/documents/ assessment-report/ketoconazole-hra-epar-public-assessmentreport_en.pdf. Accessed 28 Jun 2021.

55. Data on file, HRA Pharma Rare Diseases, 2020.

56. Nieman L, Boscaro M, Scaroni C, et al. PROMPT: a prospective study to assess efficacy and safety of metyrapone in endogenous Cushing's syndrome - 12-week interim analysis [poster no. 1107]. In: 22nd European Congress of Endocrinology; 2020.

57. Nieman LK, Boscaro M, Scaroni CM, et al. Metyrapone treatment in endogenous Cushing's syndrome: results at week 12 from PROMPT, a prospective international multicenter, open-label, phase III/IV study. J Endocr Soc. 2021;5(Suppl_1):A515.

58. Data on file, HRA Pharma Rare Diseases, 2021.

59. Daniel E, Aylwin S, Mustafa O, et al. Effectiveness of metyrapone in treating Cushing's syndrome: a retrospective multicenter study in 195 patients. J Clin Endocrinol Metab. 2015;100(11):4146-54.

60. Valassi E, Crespo I, Gich I, et al. A reappraisal of the medical therapy with steroidogenesis inhibitors in Cushing's syndrome. Clin Endocrinol (Oxf). 2012;77(5):735-42.

61. van den Bosch OF, Stades AM, Zelissen PM. Increased long-term remission after adequate medical cortisol suppression therapy as 
presurgical treatment in Cushing's disease. Clin Endocrinol (Oxf). 2014;80(2):184-90.

62. Obinata D, Yamaguchi K, Hirano D, et al. Preoperative management of Cushing's syndrome with metyrapone for severe psychiatric disturbances. Int J Urol. 2008;15(4):361-2.

63. Vassiliadi DA, Tsagarakis S. Diagnosis and management of primary bilateral macronodular adrenal hyperplasia. Endocr Relat Cancer. 2019;26(10):R567-81.

64. Omori N, Nomura K, Omori K, et al. Rational, effective metyrapone treatment of ACTH-independent bilateral macronodular adrenocortical hyperplasia (AIMAH). Endocr J. 2001;48(6):665-9.

65. Yoshida M, Umeda H, Iwama S, et al. Assessment of long-term efficacy and safety of metyrapone monotherapy in a patient with ACTH-independent macronodular adrenal hyperplasia. Endocrine. 2012;41(1):160-1.

66. Halioui-Louhaichi S, Azzabi O, Nefzi L, et al. Treatment with metyrapone of Cushing's syndrome revealing McCune-Albright syndrome. Arch Pediatr. 2005;12(7):1120-3.

67. Debono M, Harrison R, Chadarevian R, et al. Resetting the abnormal circadian cortisol rhythm in adrenal incidentaloma patients with mild autonomous cortisol secretion. J Clin Endocrinol Metab. 2017;102(9):3461-9.

68. Puglisi S, Perotti P, Barbot M, et al. Preoperative treatment with metyrapone in patients with Cushing's syndrome due to adrenal adenoma: a pilot prospective study. Endocr Connect. 2018;7(11):1227-35.

69. Corcuff JB, Young J, Masquefa-Giraud P, et al. Rapid control of severe neoplastic hypercortisolism with metyrapone and ketoconazole. Eur J Endocrinol. 2015;172(4):473-81.

70. Verhelst JA, Trainer PJ, Howlett TA, et al. Short and longterm responses to metyrapone in the medical management of 91 patients with Cushing's syndrome. Clin Endocrinol (Oxf). 1991;35(2):169-78
71. Thorén M, Adamson U, Sjöberg HE. Aminoglutethimide and metyrapone in the management of Cushing's syndrome. Acta Endocrinol (Copenh). 1985;109(4):451-7.

72. Britton S, Thoren M, Sjoberg HE. The immunological hazard of Cushing's syndrome. Br Med J. 1975;4(5998):678-80.

73. Child DF, Burke CW, Burley DM, et al. Drug controlled of Cushing's syndrome. Combined aminoglutethimide and metyrapone therapy. Acta Endocrinol (Copenh). 1976;82(2):330-41.

74. Beck KR, Thompson GR, 3rd, Odermatt A. Drug-induced endocrine blood pressure elevation. Pharmacol Res. 2020;154:104311.

75. Valassi E, Aulinas A, Glad CA, et al. A polymorphism in the CYP17A1 gene influences the therapeutic response to steroidogenesis inhibitors in Cushing's syndrome. Clin Endocrinol (Oxf). 2017;87(5):433-9.

76. Newell-Price J, Pivonello R, Tabarin A, et al. Use of late-night salivary cortisol to monitor response to medical treatment in Cushing's disease. Eur J Endocrinol. 2020;182(2):207-17.

77. Kann PH, Munzel M, Hadji P, et al. Alterations of cortisol homeostasis may link changes of the sociocultural environment to an increased diabetes and metabolic risk in developing countries: a prospective diagnostic study performed in cooperation with the Ovahimba people of the Kunene region/northwestern Namibia. J Clin Endocrinol Metab. 2015;100(3):E482-6.

78. Kumari M, Shipley M, Stafford M, et al. Association of diurnal patterns in salivary cortisol with all-cause and cardiovascular mortality: findings from the Whitehall II study. J Clin Endocrinol Metab. 2011;96(5):1478-85.

79. Yoshida K, Fukuoka H, Odake Y, et al. Multiple salivary cortisol measurements are a useful tool to optimize metyrapone treatment in patients with Cushing's syndromes treatment: case presentations. Front Endocrinol (Lausanne). 2017;8:375. 